Acta vet. scand. $1971,12,307-309$.

Brief Communication

\title{
DISC ELECTROPHORETIC STUDIES ON AN S-CARBOXYMETHYLKERATEINE PREPARATION FROM BOVINE AND CANINE HAIR*)
}

Reduced and iodoacetate alkylated keratin, S-carboxymethylkerateine (SCMK), may be separated in components differing in molecular weight and sulphur content (Gillespie et al. 1962). Species differentiation could be accomplished by moving boundary electrophoresis of high-sulphur kerateines, $\mathrm{S}_{20, \mathrm{w}}^{\mathrm{O}} \mathbf{1 . 5 5}-\mathbf{1 . 6 5}$ (Gillespie 1963, Gillespie \& Inglis 1965). Shechter et al. (1969) observed species differences in the acrylamide electropherograms of low-sulphur kerateines, mol. w. 45,000-50,000.

In the present studies disc electrophoresis was performed on SCMK preparations with a sedimentation coefficient of approx. 1.5 $\mathrm{S}$. The SCMK was obtained by disodiumsulfide reduction and iodoacetate alkylation of hair from cows and dogs, and gelfiltration of this material on Sepharose $4 \mathrm{~B}$ produced two and three fractions respectively from the two species. Only one component with an $\mathrm{S}_{20, \mathrm{w}}$ value $(0.02 \%$ nitrogen) of 1.5 and 1.7 for ox and $\operatorname{dog}$ respectively was revealed by analytical ultracentrifugation of the last fraction in the chromatogram, while the other fractions contained several components with sedimentation coefficients in the range of approx. $3-33 \mathrm{~S}$.

Supernatants from acid precipitation of SCMK from three cows (Holstein-Friesian, Red Danish Milk Breed and CharolaisJersey) and three dogs (Cocker Spaniel, Cross bred and Alsatian) were obtained by dialysis against an acetate buffer $\mathrm{pH} 4.4$, conductivity $5.0 \mathrm{mS}$ and centrifugation at $750 \times \mathrm{g}$ for $15 \mathrm{~min}$. The supernatants appeared homogeneous on Sepharose $4 \mathrm{~B}$, and the elution site indicated a sedimentation coefficient of approx. 1.5 $\mathrm{S}$.

The disc electrophoresis was performed in a Canalco apparatus using a loading gel of $1 \%$ agar and a $5 \%$ (w/v) polyacrylamide stacking gel with a $4: 1$ ratio $(\mathrm{w} / \mathrm{w})$ of acrylamide and bisacrylamide. The polyacrylamide concentration of the sep-

*) Supported by a grant from Statens jordbrugs- og veterinærvidenskabelige Forskningsråd. 
arating gel was $10.4 \%(\mathrm{w} / \mathrm{v})$ with an acrylamide: bisacrylamide ratio (w/w) of 24.1:0.9. The gel buffer was a tris buffer containing $6 \mathrm{M}$ urea as a disaggregating agent. Two hundred $\mu \mathrm{g}$ of the sample was applied to each gel. The electrophoresis buffer was a tris-glycine buffer $\mathrm{pH} 8.5$, conductivity $0.5 \mathrm{mS}$, and a constant current of 5 mamp. per gel was used for $45 \mathrm{~min}$. at $20^{\circ} \mathrm{C}$. In the upper bath a few drops of a $0.005 \%$ bromphenol blue solution was used to indicate the position of the migrating front. Following electrophoresis the gels were cut at the migrating front. The gels were fixed in a solution of $5 \%$ trichloroacetic and $7.5 \%$ acetic acid for $24 \mathrm{hrs}$. and stained with $0.25 \%$ coomassie blue in $10 \%$ acetic acid for $1 \mathrm{hr}$. Destaining was performed by several washings with $10 \%$ acetic acid. The gels were stored in $10 \%$ acetic acid in glass tubes and photographed in a $9 \times 12$ cm view camera.

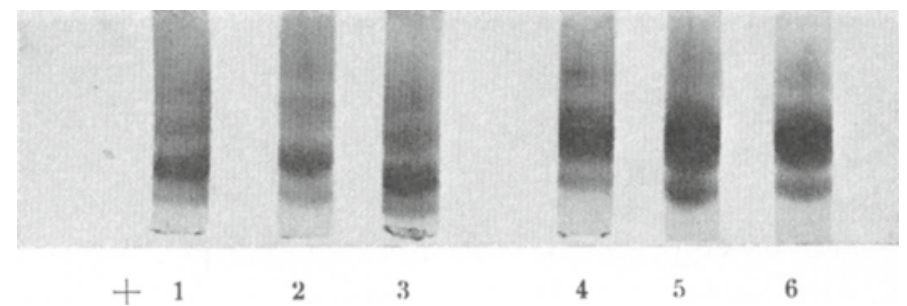

F ig u r e 1. Acrylamide disc electrophoretic patterns of $1.5 \mathrm{~S}$ fractions of SCMK from dogs $(1-3)$ and cows $(4-6) .1 .1 \times$.

It may be seen (Fig. 1) that the canine material, starting at the cathode, has been separated into two weak bands followed by a dense and a weak band, while the bovine electropherogram contains two weak bands followed by a rather wide and dense band, a narrow weak band and a distinct, dense band. Thus inter-species differences as well as intra-species homologies have been demonstrated. This indicates that species differentiation between $1.5 \mathrm{~S}$ fractions derived from bovine and canine SCMK may be accomplished on the basis of acrylamide disc electrophoresis.

\section{ACKNOWLEDGEMENTS}

The Carlsberg Breweries Research Laboratory kindly serviced the analytical ultracentrifugations. The author is grateful to Miss Bente Thorsen for skilled technical assistance. 
H. B. Simonsen

The Department of Forensic and State Veterinary Medicine, Royal Veterinary and Agricultural University, Copenhagen, Denmark.

\section{REFERENCES}

Gillespie, J. M., I. J. O'Donnell \& E. O. P. Thompson: The interaction between high- and low-sulphur proteins extracted from $\alpha$-keratin. Aust. J. biol. Sci. 1962, 15, 409-412.

Gillespie, J. M.: The isolation and properties of some soluble proteins from wool. Aust. J. biol. Sci. 1963, 16, 241-251.

Gillespie, J. M. \& A. S. Inglis: A comparative study of high-sulphur proteins from $\alpha$-keratins. Comp. Biochem. Physiol. 1965, 15, 175-185.

Shechter, Y., J. W. Landau \& V. D. Newcomer: Comparative disc electrophoresis of hair kerateines. J. invest. Dermatol. 1969, 52, $57-62$.

(Received May 4, 1971). 